\title{
Financial Viability of Residential Photovoltaic and Battery Systems in Californias
}

\author{
Jonas Lehr ${ }^{2}$, Evangelos Vrettos ${ }^{1}$, Ram Rajagopal ${ }^{2}$, Rishee Jain $^{2}$ \& Martin Everts ${ }^{3}$ \\ ${ }^{1}$ Power Systems Laboratory ETH Zurich, Zurich, Swiss \\ ${ }^{2}$ Civil and Environmental Engineering, Stanford University, Stanford, USA \\ ${ }^{3}$ Energy Economics, Axpo Holding AG, Baden, Switzerland \\ Correspondence: Jonas Lehr, Civil and Environmental Engineering, Stanford University, Stanford, USA. E-mail: \\ jonas.lehr@outlook.com
}

Received: April 30, 2017

Accepted: September 22, 2017 Online Published: October 25, 2017

doi:10.5539/jms.v7n4p16

URL: http://doi.org/10.5539/jms.v7n4p16

\begin{abstract}
Using a battery on a household level has become easier after the launch of Tesla's Powerwall. Storing electricity during daytime's PV overproduction or charging the battery during night with an attractive tariff is the most prominent applications. This paper explores the economic impact of the usage of residential battery storage combined with solar photovoltaics (PV) based on real load data from Northern California, USA. A data-driven, deterministic model to benchmark electricity cost savings for single households is presented and the financial viability of such systems is scrutinized for California. Our results indicate that under current capacity and price points, battery systems have limited financial viability and have a payback period exceeding 20 years in most cases. We deepen our analysis and compare the results of our deterministic model to that of a stochastic model to demonstrate that for an hourly time resolution the deterministic model provides an adequate benchmark for estimating cost (within 3\%) savings with a short (1/60th) computation time.
\end{abstract}

Keywords: solar PV, battery, profitability estimation

\section{Introduction}

While costs to install PV systems have dropped, the number of residential PV installations has been rising during the past years in California (according to California energy commission (2015), the average price of PV panels dropped in California from 2006 to 2013 by $50 \%$, whereas the yearly installed capacity of residential houses increased by almost 6 times).

Due to their intermittent nature, the increasing PV penetration will likely increase the need for measures to mitigate the effects on transmission and distribution levels. Batteries recently received more attention as a potential measure due to some prominent launches, such as Tesla's Powerwall and price reductions (according to Nykvist \& Nilsson (2015), the capacity price of electric vehicle batteries fell on average by about $15 \%$ per year).

Thus, on a local level, houses with PV-panels could install storage in order to shift the overproduction of noon to the evening hours. An important problem that occurs while combining distributed generation with the actual grid topology is that distribution grids may not be designed to withstand overproduction occurring through infeed of distributed generation. The benefits of combining (battery-) storages with distributed PV are apparent: the grid stability on the distribution level is preserved and if the roundtrip efficiency is high, losses can be reduced. Therefore, in order to define the financial viability of such systems, the potential electricity cost savings for single households are quantified in monetary terms and are contrasted with the investment costs for PV/battery systems.

Papers like Ha et al. (2007), Molderink et al. (2010) and Oldewurtel et al. (2010) investigate optimal demand response schemes and load management mostly for residential customers with time dependent and sometimes dynamic (real time) pricing while focusing on the methodology of the assessment rather than the quantification of the results.

Weniger et al. (2014) discuss sizing of residential PV battery systems and their economic viability. The authors use an optimization algorithm to find the cost minimizing PV/battery-size combination and conclude 
that, if the PV/battery system is sized accordingly, itis going to be financially viable. The underlying costs to calculate the financial viability however are not derived from empirical data (including installation, costs for surface etc.) but only take into account actual investment costs for buying the system components. In addition, eventual future cost reductions are estimated and contribute to the author's positive conclusion. Suzuki et al. (2012) develop a model to optimally plan and operate residential PV systems combined with battery storage.

Vrettos et al. (2013) develop a detailed battery model for households including a variety of appliances (uncontrollable loads, heat pump etc.) to maximize PV selfconsumption. A typical demand profile and different battery configurations are used to derive well-performing rule-based controllers for batteries and heat pumps to analyze the financial viability of such systems.

Vrettos et al. (2013) use a model predictive control algorithm to realistically simulate demand response of houses with multiple loads including a thermal model of the house and weather conditions within different price environments. The authors concentrate on developing a realistic control algorithm to determine the potential of the demand response of residential buildings.

Nelson et al. (2006) analyze hybrid systems including fuel cells. Fuel cells that are hardly available for residential customers are used to derive optimal sizing and to assess the economic viability of such systems.

Upadhyay \& Sharma (2014) review the sizing, control and effects to be considered in a cost/benefit analysis of hybrid systems (i.e., renewables (RES) combined with nonrenewables and/or storage).

$\mathrm{Lu} \&$ Shahidehpour (2005) develop an algorithm for short-term scheduling of batteries in security-constrained unit commitment, which aims at replicating a realistic battery control as accurately as possible, while taking into account grid constraints and locational prices to reduce electricity costs.

Other papers, such as Kaldellis et al. (2009), Vrettos \& Papathanassiou (2011) or Zhao et al. (2014) evaluate the case of sizing and controlling renewable energy sources combined with storage on islands or remote areas. The underlying situation is special, since uncommon constraints and price environments compared to most residential houses exist. Grid access is impossible or extremely expensive, and the alternate source of electricity is mostly considered to be a conventional fuel driven generator. Since most of these studies also consider islands located in areas with high sunshine (and islands have a higher degree of wind exposure), these resulting storage/RES systems become quickly financially viable.

This paper contributes to the literature in multiple ways. Most importantly, in contrast to most literature it uses a large amount of real load data in a typical cost environment of residential customers to model potential savings through the usage of PV/battery systems. It takes into account empirical investment costs including e.g. installation costs to draw a realistic picture of the actual monetary benefits resulting from using those systems and to consequently estimate their financial viability. Thereby, two different modeling approaches are used: A deterministic optimization to give an upper bound for savings and a stochastic optimization, which takes into account the uncertainty of solar radiation and electricity consumption. Both approaches are compared in terms of results and computational time to show that a deterministic modeling approach is suitable in order to benchmark the potential savings on a per customer basis.

\section{Data}

A sample of 1924 realized load profiles in hourly resolution of residential customers for one year from 486 Zip Codes in Northern California from a local utility were used in the modeling approach to estimate the monetary savings potential for residential battery users in California.

According to the literature (see Li \& Zio, 2012 or Mena et al., 2014) the solar radiation is modeled with a $\beta$-distribution. Data were taken from the National Solar Radiation Database Wilcox (2012). Every customer's ZIP-Code was matched with the closest Class I meteorological station (Class I from I-III, here data are of highest possible quality). Further explanations can be found in the Appendix. The Trina Solar TSM-245PA05A, 245 Watt Solar Panel was used. The efficiency of the panel is $15 \%$, and the system size is $64.95 \times 39.05$ inches (about $1.6 \mathrm{~m} 2$ ). This results in a possible installation of $150 \mathrm{~W} / \mathrm{m}^{2}$.

The most commonly used panel sizes according to California energy commission (2015) were: 0, 2, 4, 6 and $8 \mathrm{~kW}$. Average total costs (including installation) according to the same source were used (detailed costs can be found in the appendix). The specifications of the Powerwall model daily cycle were taken from the press release of Tesla [8] as simulation basis (state of data correspond to time of the preparation of the paper and are listed in Table 1). To model the degradation of the battery's capacity, data from NREL DiOrio et al. (2015) were used, in which for the best case of a Li-ion battery, $65 \%$ of its initial capacity is reached after $\sim 10^{\prime} 000$ 
and for the worst case after $\sim 4^{\prime} 000$ cycles. In the following, these two cases are used for benchmarking reasons and a model of degradation is derived. Model of battery degradation:

Table 1. Tesla's Powerwall Specification based on its press release.

\begin{tabular}{ll}
\hline Type & Daily Cycle \\
\hline Storage capacity $[\mathrm{kWh}]$ & 7 \\
Continuous power $[\mathrm{kW}]$ & 2 \\
Peak power [kW] & 3.3 \\
Round trip efficiency [\%] & 92 \\
Inverter efficiency [\%] & 95 \\
Charge/discharge efficiency ${ }^{a}[\%]$ & 96 \\
Warranty [years] & 10 \\
Number of cycles warranted & 25000 \\
Costs [USD] & $3^{\prime} 000^{b} / 7^{\prime} 000^{c}$ \\
Price of $1 \mathrm{kWh}{ }^{d}[\$]$ & 0.12 \\
\hline
\end{tabular}

Note. ${ }^{a}$ Estimated by square root of round trip efficiency. ${ }^{b}$ Based on release, capital costs only. ${ }^{c}$ Based on offer from SolarCity, incl. inverter and installation. Used for further analysis. ${ }^{d}$ Based on the guaranteed cycle number and capital costs only, w.o. depreciation.

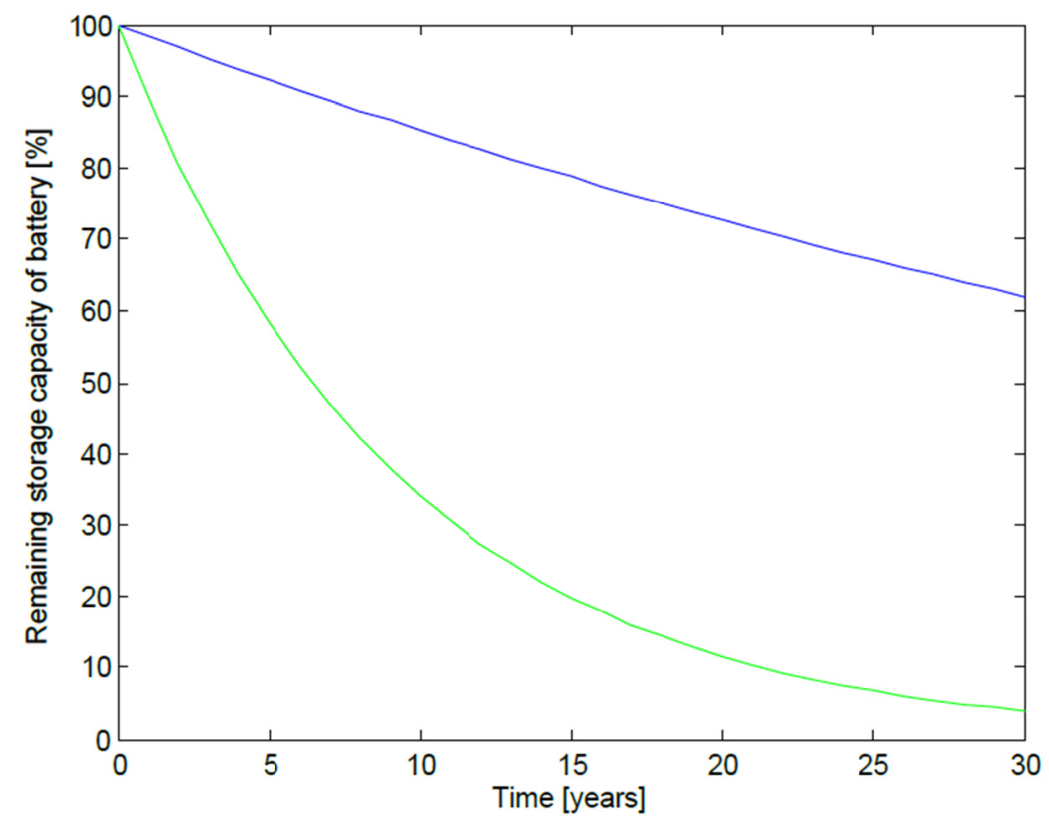

Figure 1. Remaining DOD for best and worst case of battery capacity degradation as a function of battery age

$$
C_{r}(t)=a \times e^{b \times t}
$$

For both models, a is equal to 100 and $b$ is -0.118 for the worst case model, -0.016 for the best case model respectively. $t$ represents the age of the battery, $C_{r}(t)$ stands for the remaining storage capacity of the battery in percent of the original capacity. Figure 1 depicts $C_{r}(t)$ for the battery modeled as a function of its lifetime. 
Table 2. Rate scheme of P\&GE for electric vehicles

\begin{tabular}{lllll}
\hline $\begin{array}{l}\text { Price } \\
{[\text { cents } / \mathrm{kWh}]}\end{array}$ & $\begin{array}{l}\text { Off- } \\
\text { Peak }\end{array}$ & $\begin{array}{l}\text { Half- } \\
\text { Peak }\end{array}$ & Peak & FIT \\
\hline Winter $^{a}$ & 10 & 17 & 29 & 8.92 \\
Summer $^{b}$ & 10 & 22 & 42 & $8.92^{c}$
\end{tabular}

Note. ${ }^{a}$ Oct-Apr, Off-Peak: 22-11, Half-Peak: 11-14 and 20-22, Peak: 14-20 o'clock. ${ }^{b}$ May-Sept, Off-Peak: 22-11, Half-Peak: 11-14, Peak: 14-22 o'clock. ${ }^{c}$ The current average FIT in California, according to Commission (2015).

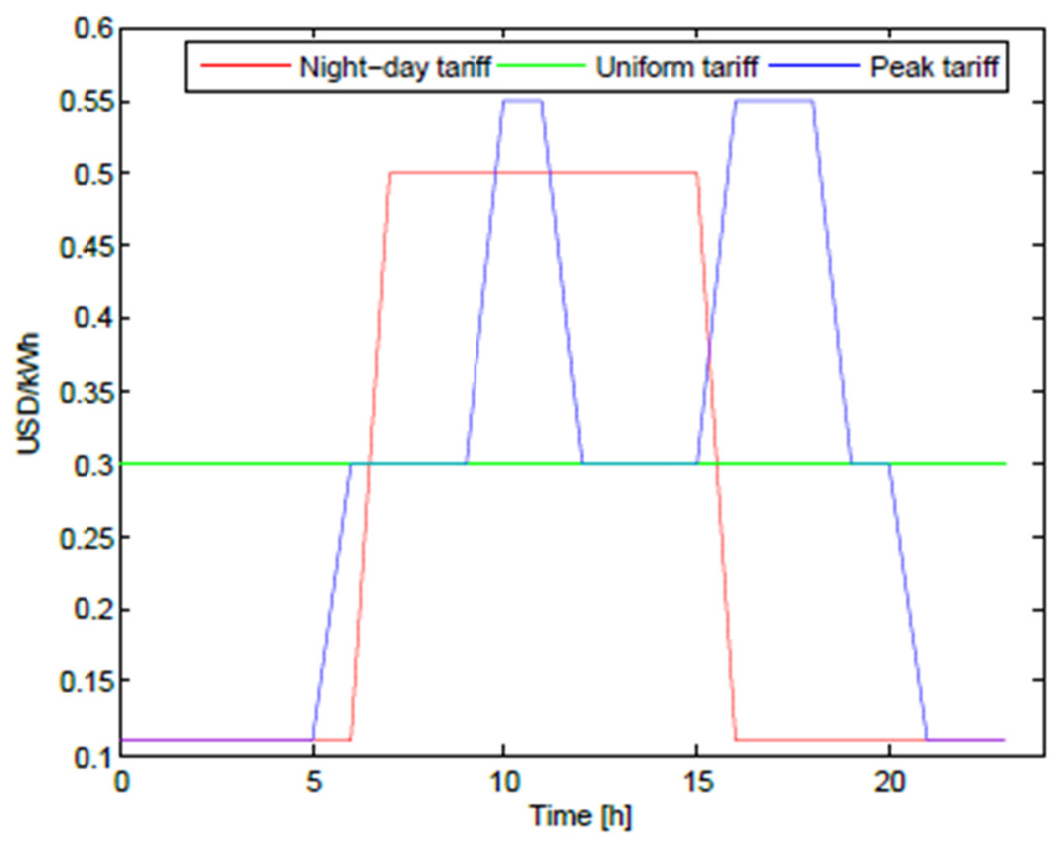

Figure 2. Tariff structures used for parametric analysis

Many different rate schemes exist in Northern California and until now, no rate exists for clients possessing a battery installation at home. Consequently, the rate plan of PG\&E for clients having electric vehicles was chosen as basis (listed in Table 2).

Three different tariff schemes were designed to evaluate the battery's reaction on differing tariff structures. The tariff structures used for the parametric analysis are depicted in Figure 2.

\section{Methods-Deterministic Model}
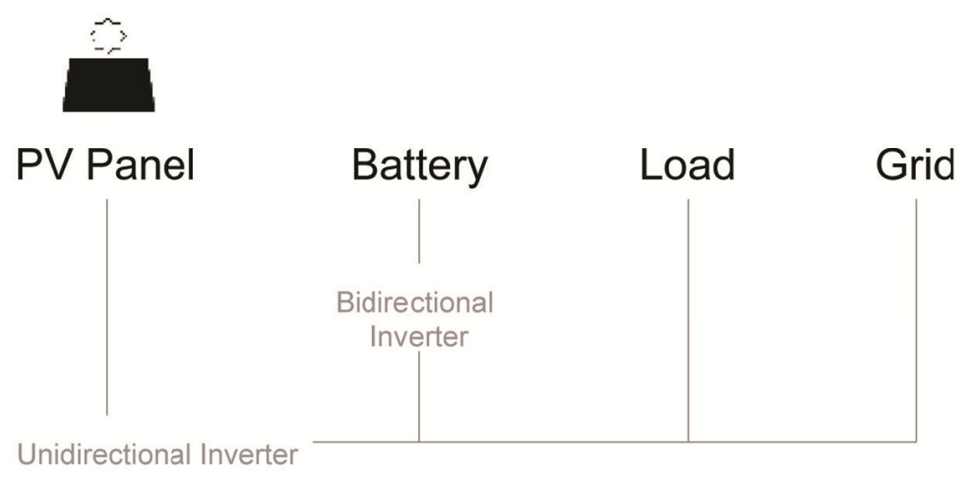

Figure 3. Overview on house with PV, battery and grid connection 
The deterministic model was set up as follows. The house (load) is able to choose whether to (dis-)charge the battery or use the grid to buy or sell electricity and is depicted in Figure 3. The overall goal of the model was to minimize the costs of electricity consumption for a household with PV, battery storage and a given load profile, resulting in a net-load profile with grid-import and -export and the minimized costs for a specific time period. CVX, a Matlab software to solve convex optimization problems was used.

$$
\begin{gathered}
t=\text { end } \\
\sum\left(r_{t} \times g^{i} t-F I T_{t} \times g^{e} t\right) \\
t=1 \\
\text { minimize } \\
\text { subject to } \\
l_{t}^{n e \iota}+\delta_{t}^{c}-\delta_{t}^{u}+g_{t}^{c}-g_{t}^{e}=0 \\
0 \leq g_{t}^{e} \leq \operatorname{cap}^{\max _{i n}} \\
0 \leq g_{t}^{e} \leq \operatorname{cap}^{\text {max }_{\text {out }}} \\
0 \leq \delta_{t}^{d} \leq \delta^{\operatorname{maxd}} \\
0 \leq \delta_{t}^{c} \leq \delta^{\max _{c}} \\
0 \leq \operatorname{soct}^{\max } \\
\operatorname{soc}_{t}(t=1)=\operatorname{soc}_{t}(t=0) \\
\operatorname{soc}_{t}(t+1)=\operatorname{soc}_{t}(t) \times \operatorname{soc}^{l}+ \\
\delta_{t}^{c}(t) \times \eta_{c}-\delta_{t}^{a}(t) \times 1 / \eta_{c}
\end{gathered}
$$

yt
$e$ : electricity import from the grid $[\mathrm{kW}]$

$\mathrm{g}_{\mathrm{t}}$ : electricity export to the grid $[\mathrm{kW}]$

soc $_{\mathrm{t}}$ : the battery's state of charge [kWh]

$\operatorname{soc}^{1}$ : the battery's self-discharge rate [-]

$1_{t}^{\text {net: }}$ net load profile $[\mathrm{kW}]$

cap $^{\text {maxin/out }}$ : the maximal line capacity to/from the grid $[\mathrm{kW}]$

$\mathrm{r}_{\mathrm{t}}$ : profile of the tariff $[\$ / \mathrm{kWh}]$

$\mathrm{FIT}_{\mathrm{t}}$ : feed-in-tariff $[\$ / \mathrm{kWh}]$

$\delta^{\text {maxc/d}: ~ m a x ~ c h a r g e ~ a n d ~ d i s c h a r g e ~ r a t e ~ o f ~ t h e ~ b a t t e r y ~}[\mathrm{~kW}]$

$\delta_{\mathrm{t}}^{\mathrm{c}}$ : the battery's rate of charge $[\mathrm{kW}]$

${ }^{t}$ : the battery's rate of discharge $[\mathrm{kW}]$

$\eta_{\mathrm{t}}$ : the battery's charging efficiency, as derived from round-trip efficiency, discharging efficiency $\eta_{\mathrm{d}}={ }^{\wedge} 1 / \eta_{\mathrm{c}}[-]$

$\mathrm{c}^{\max }$ : max battery capacity $[\mathrm{kWh}]$

Note. a Import from and export to the grid were defined as separate variables, so that setting the FIT to zero, export is eliminated without changing constraints. $b$ The net load profile is the difference between the household's load profile and PV-production.

Jonas (2011) proposes a further constraint. The product of the charging and discharging operation must be zero for all times, so that only either one of both takes place.

The implementation of this constraint is not needed here: as the buying price is always positive and efficiency is less than one, each simultaneous charge and discharge operation would waste electricity and thus increase the electricity costs. As the objective is to minimize those costs, these actions never take place simultaneously (which was tested and verified).

\section{Methods-Scenario based Stochastic Optimization}

In order to better account for the uncertainty, a scenario based stochastic optimization is presented here.

The model used in this paper is built up according to Bernardini \& Bemporad (2009) who give insights on how to account for uncertainty in MPC-systems and the paper of Shapiro \& Philpott (2007) which is a basic tutorial on stochastic programming. 
A number of different consumption scenarios are taken into account for every household. These scenarios (in the following called net load $(i, n, t))$, in analogy to a Monte Carlo simulation, are the basic load profiles of the households minus a random sample of electricity PV-production (according to the parameters of the household's PV installation and geographic location), plus a random term accounting for the consumption uncertainty.

$$
\text { net } \operatorname{load}(i, n, t){ }^{\wedge} \operatorname{load}(i, t)-\operatorname{PV}(i, t)+\delta_{\text {cons }}(i, t)
$$

where $\mathrm{i}$ indicates the household and $\mathrm{n}$ the scenario. The consumption uncertainty is given with

$$
\delta_{\text {cons }}(i, t) \sim N\left(0, \sigma(i, t)^{2}\right)
$$

where the variance is the historic variance at a specific hour of the day. For very few hours during night, negative demand can occur in the scenarios, as a normal distribution with zero mean is added. These cases are set to zero.

The objective of this model and its constraints are the same as for the deterministic formulation. However, only the current net load is known. Therefore, the optimization is carried out from the current state to the optimization's horizon $T$ for all scenarios $n \in N$.

$$
\begin{aligned}
\underset{\text { minimize }}{r_{1} \times} g_{1}^{i}-F I T_{1} \times g_{1}^{e}+ \\
\sum_{t=2}^{T} \sum_{n=1}^{N} E\left[r_{t, n} \times g_{t, n}^{i}-F I T_{t} \times g_{t, n}^{e}\right]
\end{aligned}
$$

subject to

$$
\begin{aligned}
& l t, n n e t+\delta t, n c-\delta t, n d+g t, n e-g t, n i=0 \\
& 0 \leq g_{t, n}^{i} \leq \operatorname{cap}^{\max _{i n}} \\
& 0 \leq g_{t, n}^{e} \leq \operatorname{cap}^{\text {max }_{\text {out }}} \\
& 0 \leq \delta t, n d \leq \delta \text { maxd } \\
& 0 \leq \delta t, n c \leq \delta \operatorname{maxc} \\
& 0 \leq \text { soct, } n \leq \text { cmax } \\
& \operatorname{soc}_{t, n}(t=1)=\operatorname{soc}_{t, n}(t=0) \operatorname{soc}_{t, n}(t+1)=\operatorname{soc}_{t, n}(t)+ \\
& \delta t, n c(t) \times \eta c-\delta t, n d(t) \times 1 / \eta c
\end{aligned}
$$

where $E[.$.$] represents the expected value for the future.$

After the optimization is carried out for a single time step (in this case an hour) and its optimization horizon, time is moved forward, the 'real' value for the next time step is taken and a new expectation for the coming time steps is derived. The SOC of the battery is the only memory which is carried from one hour to the next.

The expected value can be derived in many ways. In this context, an autoregressive integrated moving average ARIMA $(24,1,1)$ time series model was used. The differencing $(D=1)$, was applied to remove the trend, as looking at the plots of the autocorrelation function (ACF) and partial autocorrelation function (PACF) suggested that an autoregressive process with a lag=24 and a moving average process with lag=1 was prevalent.

Typical household consumption is subject to daily seasonality which is represented with the AR(24) part. The dependence on the last hour is expressed with the MA(1) part. The t-statistics for the tested time series were highly significant for the MA and AR part and support the choice of the model.

For the actual simulation, the net load (including added consumption uncertainty) from the previous week was taken as a training set and the last 24 hours of the Monte Carlo scenario were taken as predictors. The prediction horizon has the same length as the optimization horizon, for which 24 hours seemed to be reasonable. An advantage of using the ARIMA-model in comparison to taking other, simpler techniques to derive the expected value, is that the standard error of the estimation is provided which can be used to e.g. run a simulation for the $95 \%$ percentiles of net load.

For a given payback time, monetary savings incurred in year $t$ to the customer from the installation of the 
$\mathrm{PV} /$ battery systems were calculated as follows:

savings $(\mathrm{t})=\mathrm{e}-$ costs $(\mathrm{t})$ prior $-\mathrm{e}-\mathrm{cost} \mathrm{t})$ installation

where e-costs are the electricity costs of the customer, the index prior stands for the costs without any $\mathrm{PV} /$ battery and the index installation for all possible combination of PV/battery systems.

For year $t$ the distribution of solar radiation, the PV-panel characteristics, the electricity consumption and the electricity tariffs were assumed to stay the same. The maximal storage capacity of the battery however was assumed to change due to degradation.

The NPV is calculated based on the following formula

$$
\mathrm{NPV}=\sum_{t=:}^{t=\text { end }} \frac{S_{t}}{(1+r)^{t}}-C_{0}
$$

where $S_{t}$ stands for the savings incurred in time period $t$ in USD, $r$ the discount rate in $\%$ and $C_{0}$ the investment costs in USD. Here, discount rates of 2, 5, and $8 \%$ were applied and the investment costs represent the costs for buying and installing the battery and PV in the sizes indicated.

The payback time (or break even) is defined as the time period $(t=e n d)$, for which the NPV becomes zero for the first time.

\section{Results-Deterministic Model}

To derive the marginal savings accounted to the battery (or the PV system), the occurring costs for the household equipped with a PV/Battery system were subtracted from the costs of the same household without the equipment.

The derived marginal savings through battery usage based on PG\&E tariff are shown in Figure 4. The Figure reads as follows: The boxplot represents the original distribution of electricity costs of the households. The shaded error plots represent median, $1-\sigma$ and 2- $\sigma$ intervals of the savings. Each of these plots represents one PV installation size. While increasing the battery storage capacity on the x-axis, the effect of savings through using only (Note 1) the battery is visible and can be read from the y-axis.
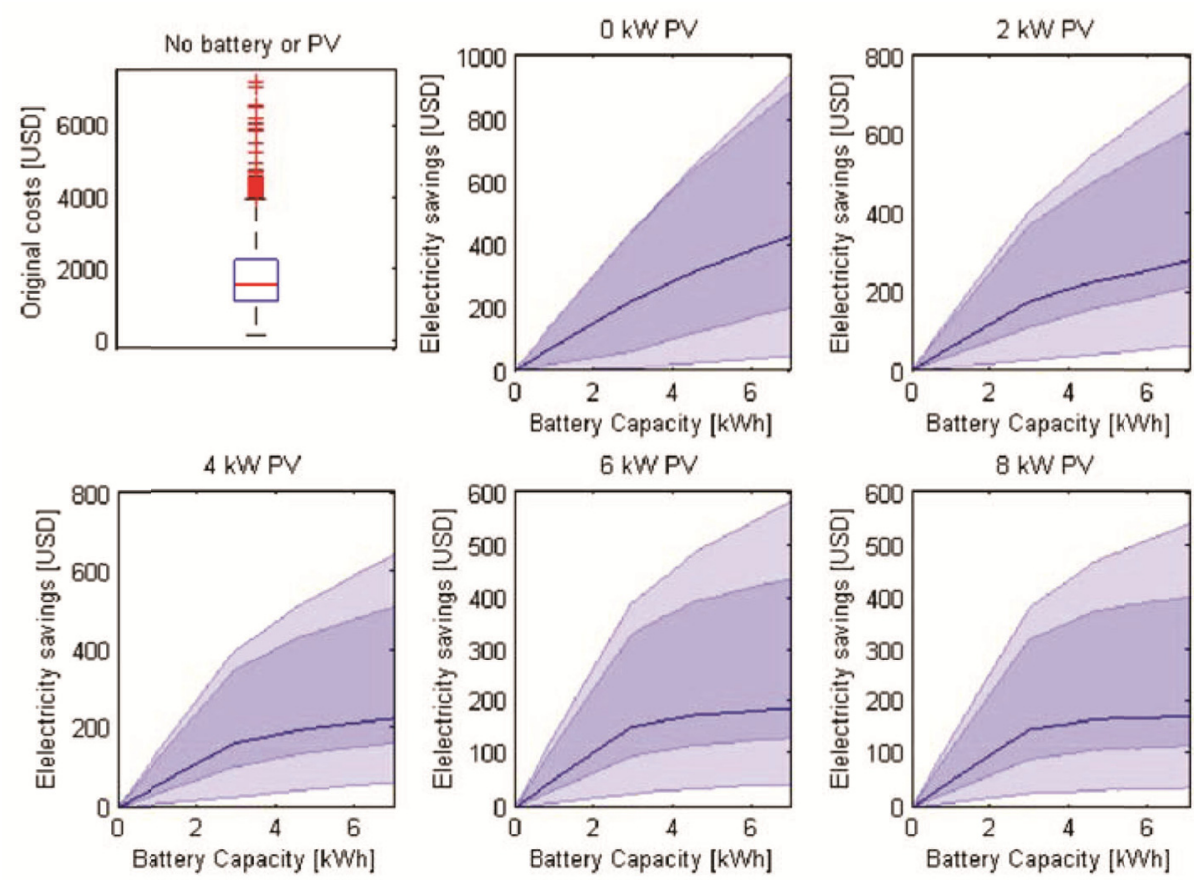

Figure 4. Yearly savings through battery usage. Costs are shown in boxplot, median, $1 \sigma$ and $2 \sigma$ of savings are shown

Figure 5 depicts the savings when comparing households equipped with a battery only and those equipped with a battery and PV (Note 2). It can be seen that after an initial kink at $2 \mathrm{~kW}$ capacity, the marginal savings 
are going down. Thus, combined with Figure 4 one can conclude that the Powerwall is generally oversized. It is interesting to note, that the effect of the battery is similar for tariff structures where prices differ though the day since arbitrage effects are possible.

Figure 6 depicts the payback time of PV/battery systems using the Powerwall, once for the best and once for the worst case assumed. Note that all payback times greater than 70 years were set to 70 .

It can be seen that only for the best case of battery degradation, high PV usage and a very low discount rate assumed, the payback time of the system is in a reasonable time horizon for most houses. The effect of the PV panels is due to the feed-in-tariff, which makes the system as a whole profitable (see Figure 5). In this simulation, a single battery never pays back. The red bar ( $0 \mathrm{~kW}$ PV installed) is at the maximum payback time for both cases and all discount rates assumed.

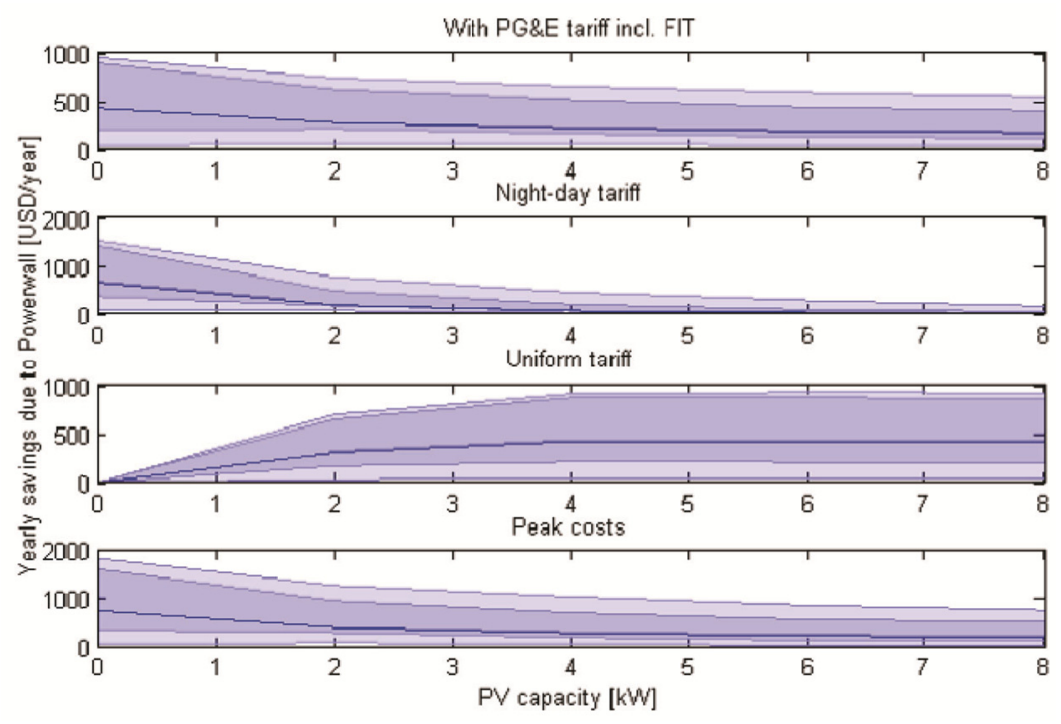

Figure 5. Savings due to Powerwall for different PV sizes and tariff profiles. Median, $1 \sigma$ and $2 \sigma$ are shown

Figure 7 shows the payback time when changing investment costs for the battery as percentage of the original investment costs. Optimistic scenarios for future development of PV and battery costs are taken: Best case scenario for battery degradation and 0,2 and $4 \mathrm{~kW}$ PV system with a discount rate of $2 \%$ were used. For better readability and since future savings only have little impact on payback time the more in the future they occur, all points higher than 50 years were set to 50 .

It can be seen that most impact on the battery payback time starts when $40 \%$ of the original battery costs are reached. Afterwards, payback time drops dramatically. For PV/battery systems, the slope is not as steep, due to the fixed costs of the PV investment.

\section{Results-Stochastic Model}

Table 3 lists the results of the comparison of the deterministic and the stochastic model. It can be seen that the outcome of the costs is fairly close, whereas the simulation time of stochastic model is much higher. Thus, it can be concluded that in this context it is sufficient to run the deterministic model. Only when the time resolution would be higher (i.e. one would work with 15 -min or minutely data), the picture would change: Part of the stochastics of the load (which is now averaged out over an hour) will enter the stochastic modeling. Consequently, the deterministic model would give results that are much more optimistic. 


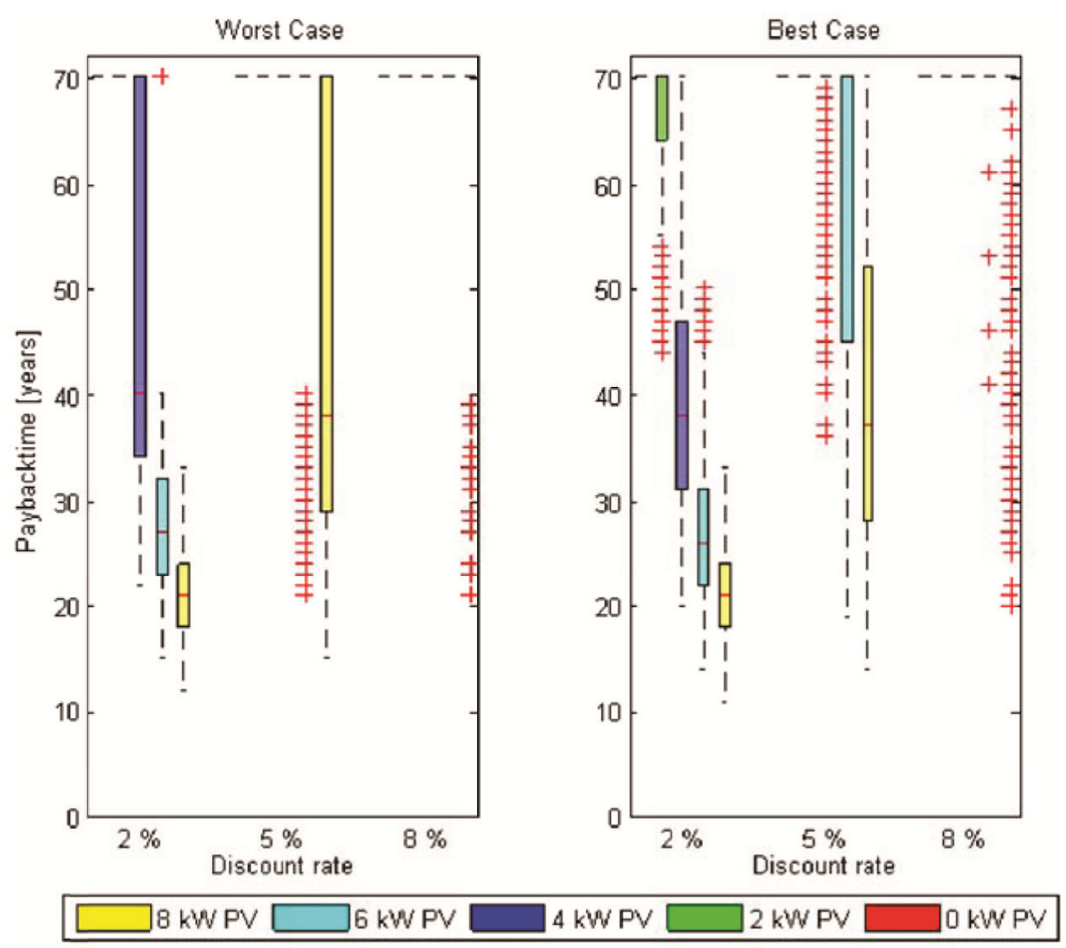

Figure 6. Payback time for different PV/battery/discount rate and degradation scenarios assumed

Table 3. Comparison of both modeling approaches in terms of computational time and potential savings.

\begin{tabular}{llc}
\hline & $\begin{array}{l}\text { Computational } \\
\text { Time }\end{array}$ & $\begin{array}{c}\text { Average } \\
\text { costs (USD) }\end{array}$ \\
\hline Load w.o. battery usage $^{a}$ & - & 61 \\
Stochastic model & 10 days & 24.7 \\
Deterministic model & 4 hours & 25.3 \\
\hline
\end{tabular}

Note. ${ }^{a}$ Cost of the original load with TOU (of net load, including PV and FIT).

\section{Conclusion}

Looking at the usage of stochastic and deterministic models to evaluate the profitability of $\mathrm{PV} /$ battery systems, it was shown that deterministic models are fast and are expected to over perform the battery control only marginally when working with hourly data. It is expected that the difference of the outcome using stochastic and deterministic models increases when working with more granular data.

While using actual consumption, tariff profiles, solar radiation and real occurring costs for PV and battery, it was shown that such systems are not cost competitive yet, even when calculating with support such as feed-in tariffs. 


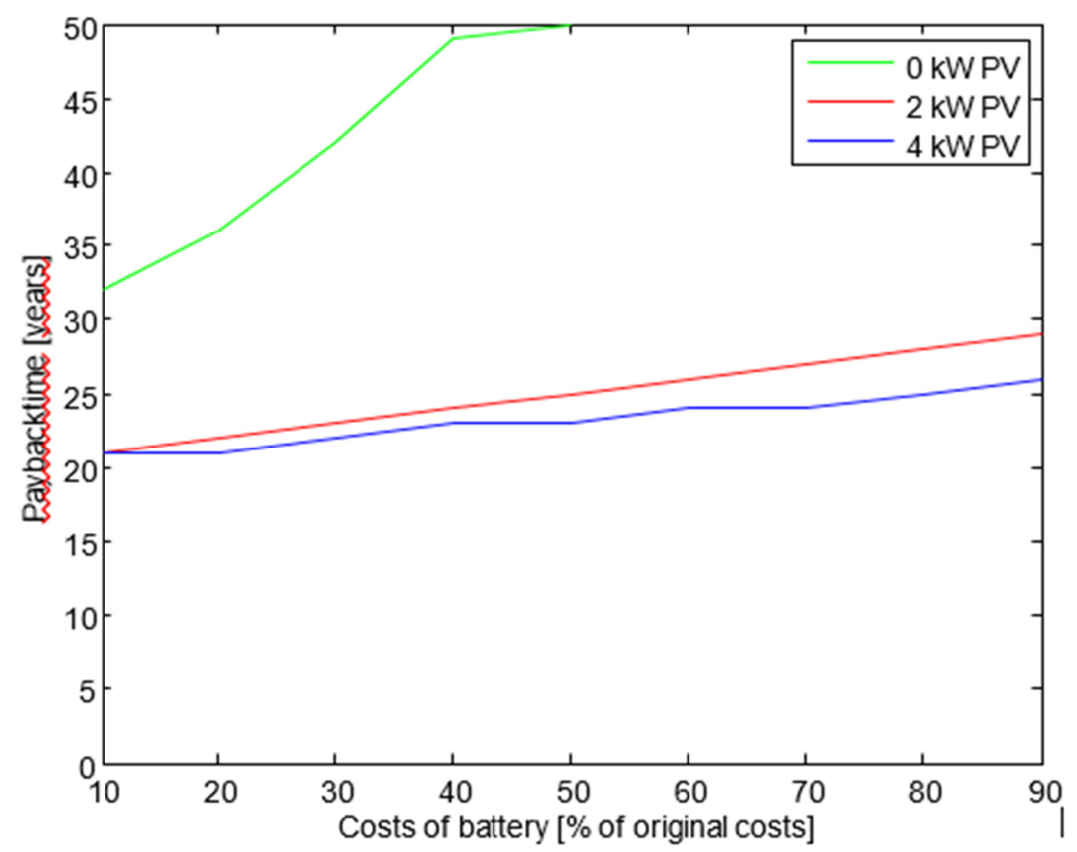

Figure 7. Payback time of PV battery systems with different PV sizes and changing battery investment costs (discount rate of $2 \%$, PG\&E tariff incl. FIT)

When running simulations with two extreme assumptions on battery degradation, payback times differed only very little (see Figure 6, e.g., $5 \% 8 \mathrm{~kW} \mathrm{PV}$ case). This, because savings from less battery degradation occur in the far future and only influence the net present value of the system marginally.

From these observations, it can be concluded that reducing price per capacity is more crucial than working on longer lasting battery performance. Since PV and battery costs per capacity dropped dramatically in the last years, and they are expected to steadily decrease the coming years, it is assumed that in the near future such systems become profitable in the short run.

\section{References}

Bernardini, D., \& Bemporad, A. (2009). Scenario-based model predictive control of stochastic constrained linear systems. In: Decision and Control, 2009 held jointly with the 2009 28th Chinese Control Conference. $\mathrm{CDC} / \mathrm{CCC}$ 2009. Proceedings of the 48th IEEE Conference on, IEEE, pp. 6333-6338. https://doi.org/10.1109/CDC.2009.5399917

California energy commission. (2015). California energy commission: Solar statistics. Retrieved from http://www.californiasolarstatistics.ca.gov

California public utility commission. (2015). California public utility commission: Feed-in-tariff overview California. Retrieved from http://docs.cpuc.ca.gov

DiOrio, N., Dobos, A., Janzou, S., Nelson, A., \& Lundstrom, B. (2015). Technoeconomic modeling of battery energy storage in sam. National Renewable Energy Laboratory, Golden. https://doi.org/10.2172/1225314

Ha, D. L., De Lamotte, F. F., \& Huynh, Q. H. (2007). Real-time dynamic multilevel optimization for demand-side load management. In: Industrial Engineering and Engineering Management, 2007 IEEE International Conference on, IEEE, pp. 945-949.

Jonas, P. A. (2011). Predictive power dispatch for 100 percent renewable electricity scenarios using power nodes modeling framework, unpublished. Master's thesis, ETH Zurich.

Kaldellis, J., Zafirakis, D., Kaldelli, E., \& Kavadias, K. (2009). Cost benefit analysis of a photovoltaic-energy storage electrification solution for remote islands. Renewable Energy, 34(5), 1299-1311. https://doi.org/10.1016/j.renene.2008.09.014

Li, Y. F., \& Zio, E. (2012). A multi-state model for the reliability assessment of a distributed generation system via universal generating function. Reliability Engineering \& System Safety, 106, 28-36. https://doi.org/10.1016/j.ress.2012.04.008 
Lu, B., \& Shahidehpour, M. (2005). Short-term scheduling of battery in a grid-connected pv/battery system. Power Systems, IEEE Transactions on, 20(2), 1053-1061. https://doi.org/10.1109/TPWRS.2005.846060

Mena, R., Hennebel, M., Li, Y. F., Ruiz, C., \& Zio, E. (2014). A risk-based simulation and multi-objective optimization framework for the integration of distributed renewable generation and storage. Renewable and Sustainable Energy Reviews, 37, 778-793. https://doi.org/10.1016/j.rser.2014.05.046

Molderink, A., Bakker, V., Bosman, M. G., Hurink, J. L., \& Smit, G. J. (2010). Management and control of domestic smart grid technology. Smart Grid, IEEE Transactions on, 1(2), 109-119. https://doi.org/10.1109/TSG.2010.2055904

Nelson, D., Nehrir, M., \& Wang, C. (2006). Unit sizing and cost analysis of standalone hybrid wind/pv/fuel cell power generation systems. Renewable Energy, 31(10), 1641-1656. https://doi.org/10.1016/j.renene.2005.08.031

Nykvist, B., \& Nilsson, M. (2015). Rapidly falling costs of battery packs for electric vehicles. Nature Climate Change, 5(4), 329-332. https://doi.org/10.1038/nclimate2564

Oldewurtel, F., Ulbig, A., Parisio, A., Andersson, G., \& Morari, M. (2010). Reducing peak electricity demand in building climate control using real-time pricing and model predictive control. In: Decision and Control (CDC), 2010 49th IEEE Conference on, IEEE, pp. 1927-1932. https://doi.org/10.1109/CDC.2010.5717458

Shapiro, A., \& Philpott, A. (2007). A tutorial on stochastic programming. Manuscript.

Suzuki, R., Hayashi, Y., \& Fujimoto, Y. (2012). Determination method of optimal planning and operation for residential pv system and storage battery based on weather forecast. In: Power and Energy (PECon), 2012 IEEE International Conference on, IEEE, pp. 343-347. https://doi.org/10.1109/PECon.2012.6450235

Upadhyay, S., \& Sharma, M. (2014). A review on configurations, control and sizing methodologies of hybrid energy systems. Renewable and Sustainable Energy Reviews, 38, 47-63. https://doi.org/10.1016/j.rser.2014.05.057

Vrettos, E., \& Papathanassiou, S. (2011). Operating policy and optimal sizing of a high penetration res-bess system for small isolated grids. Energy Conversion, IEEE Transactions on, 26(3), 744-756. https://doi.org/10.1109/TEC.2011.2129571

Vrettos, E., Lai, K., Oldewurtel, F., \& Andersson, G. (2013a). Predictive control of buildings for demand response with dynamic day-ahead and real-time prices. In: European Control Conference (ECC), Zurich, Switzerland.

Vrettos, E., Witzig, A., Kurmann, R., Koch, S., \& Andersson, G. (2013b). Maximizing local pv utilization using small-scale batteries and flexible thermal loads. EU PVSEC Weniger J, Tjaden T, Quaschning V (2014) $\begin{array}{llllll}\text { Sizing of residential PV battery systems. Energy Procedia, 46, } & 78-87 .\end{array}$ https://doi.org/10.1016/j.egypro.2014.01.160

Wilcox, S. (2012). National solar radiation database 1991-2005 update: User's manual. Tech. rep., National Renewable Energy Laboratory (NREL), Golden, CO.

Zhao, B., Zhang, X., Li, P., Wang, K., Xue, M., \& Wang, C. (2014). Optimal sizing, operating strategy and operational experience of a stand-alone microgrid on Dongfushan island. Applied Energy, 113, 1656-1666. https://doi.org/10.1016/j.apenergy.2013.09.015

\section{Notes}

Note 1. savings $=\operatorname{costs}(\mathrm{PV})-\operatorname{costs}(\mathrm{PV}, \mathrm{Battery})$, with changing battery size.

Note 2. savings $=\operatorname{costs}(\mathrm{PV})$ - $\operatorname{costs}(\mathrm{PV}$,Battery), with changing battery size and tariff structures.

\section{Copyrights}

Copyright for this article is retained by the author(s), with first publication rights granted to the journal.

This is an open-access article distributed under the terms and conditions of the Creative Commons Attribution license (http://creativecommons.org/licenses/by/4.0/). 